\title{
Sucrose Reduces Pain Reaction to Heel Lancing in Preterm Infants: A Placebo-Controlled, Randomized and Masked Study
}

\author{
HANS-ULRICH BUCHER, THIS MOSER, KURT VON SIEBENTHAL, MATTHIAS KEEL, \\ MARTIN WOLF, AND GABRIEL DUC \\ Neonatal Clinic, Department Obstetrics and Gynaecology, University Hospital, CH-8091 Zurich, \\ Switzerland
}

\begin{abstract}
In term infants sucrose given by mouth has been reported to reduce duration of crying after a heel prick. This study was designed primarily to investigate the effect of sucrose administered orally immediately before heel lancing on the nociceptive reaction in preterm infants as assessed by change in heart rate and duration of crying. A secondary objective was to document changes in cerebral blood volume during acute pain. We used a randomized, masked, placebo-controlled, crossover trial in a neonatal intermediate care unit in a level 3 perinatal center. The patients studied were 16 preterm infants; birth weight, 900-1900 g; gestational wk, 27-34; corrected postmenstrual age at time of investigation, 33-36 wk. Each infant was assessed twice receiving $2 \mathrm{~mL}$ of sucrose $50 \%$ or $2 \mathrm{~mL}$ of distilled water in random order immediately before heel lance. Heart rate, thoracic move-

ments, and transcutaneous blood gases were monitored continuously. Crying during the procedure was documented by a videocamera. A change in cerebral blood volume was assessed by near-infrared spectroscopy. We found the heart rate increased by a mean of 35 beats/min (bpm) after sucrose and 51 bpm after placebo (median difference $16 \mathrm{bpm}$, interquartile range 1-30 bpm, $p=0.005$ ). Infants cried $67 \%$ of time after sucrose and $88 \%$ after placebo (median difference $10 \%$, interquartile range $3-33 \%, p=0.002$ ). Cerebral blood volume decreased in 5 of 14 infants after sucrose and in 6 of 14 infants after placebo (difference not significant). We concluded that sucrose administered orally before a heel lance reduces the pain reaction in preterm infants. Response of cerebral blood volume to pain does not seem to be altered by sucrose. (Pediatr Res 38: 332-335, 1995)
\end{abstract}

Preterm infants usually endure many heel pricks and other stressful events during their first hospital stay, even if they do not need intensive care. There was a general belief that preterm infants are less sensitive to pain than more mature infants; as a result, analgesics and anesthetic agents were rarely used in preterm babies. There has been growing evidence in the last decade that preterm infants are anatomically and physiologically capable of feeling pain. This evidence has led to a change in clinical practice (1-3).

Pain involves subjective and emotional associations that are difficult to define in neonates. Nociception (response of the pain-reception neurones), although less often used, would be a better definition as it is a purely physiologic term (4). We use "pain" in this restricted sense of "nociception."

Reaction to pain can be assessed in three ways: 1) watching behavior, including facial expression, body movements, and cry; 2) monitoring physiologic variables, such as heart rate, blood pressure, transcutaneous blood gases; and 3) measuring the release of stress hormones, such as catecholamines and

Received Scptember 8, 1994; accepted March 14, 1995

Correspondence: H. U. Bucher, M.D., Neonatology, E Nord I 164, University Hospital, CH-8091 Zurich, Switzcrland. cortisol (5-7). For the present study monitoring of physiologic variables was chosen because they can be continuously recorded and easily quantified, and, therefore, are best suited to assess the response to an acute painful stimulus.

Different methods have been proposed to reduce pain in daily neonatal care: tactile and auditory maneuvers, pacifier, swaddling, anesthetic cream, and pharmacologic agents (810). Sucrose given orally to healthy term newborn infants during blood collection or circumcision reduces crying (11). No quantitative data have been published for preterm infants. As preterm infants usually undergo blood collection from heel prick more often than term infants, we found it important to demonstrate that sucrose also acts favorably in these immature infants.

The primary objective of this study was to evaluate the effect of $2 \mathrm{~mL}$ of $50 \%$ sucrose given orally $2 \mathrm{~min}$ before a heel lance on pain reaction assessed by an increase in heart rate. Secondary objectives were to study other physiologic characteristics, including changes in cerebral blood volume, to compare the subjective impression of pain reaction of the nurses with the recorded indices, and to investigate the influence of glycemia on the nociceptive reaction. 


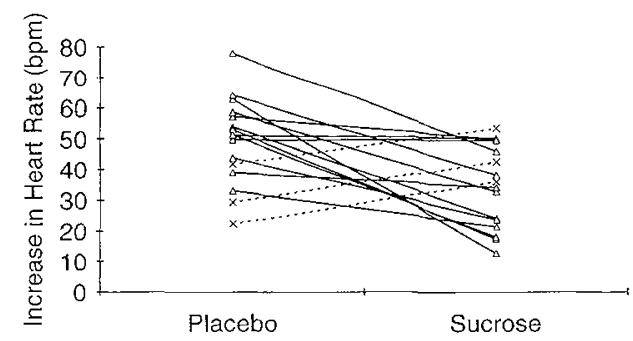

Figure 1. Effect of sucrose on increase in heart rate after a heel lance. Reduction in 13 infants (continuous line), increase in three infants (broken line). $p=0.005$.



Figure 2. Effect of sucrose on relative duration of crying during whole blood collection procedure. Reduction in 14 infants (continuous line), increase in two infants (broken line). $p=0.002$.

\section{METHODS}

Preterm infants in intermediate care who would get a clinically indicated blood sample by heel lance were enrolled in the trial. Exclusion criteria were: gestational age $>34 \mathrm{wk}$ at birth, drug dependence of the mother, malformation, intraventricular hemorrhage, intracerebral hemorrhage, cystic leukomalacia, signs or symptoms of acute illness, and any medication except vitamins in the last $3 \mathrm{~d}$ before the study.

Every infant was assessed twice; each baby received sucrose or water in random order. Vials containing 50\% sucrose or distilled water were prepared in the hospital pharmacy. Using a table of random numbers sucrose was coded with a or b, and water with the complement. The vials were brown, and the contents could not be identified by eye.

The evaluation was done between 0900 and $1200 \mathrm{~h}$ at least $60 \mathrm{~min}$ after the last feed. The infants were placed in prone position under a radiant warmer in a separate room with constant lighting and low noise. The infants were dressed only with a light vest and diapers.

Heart rate and respiratory movements were assessed by a standard cardiorespirograph (Servomed, Hellige, Freiburg, Germany). $\mathrm{Po}_{2}$ and $\mathrm{PCO}_{2}$ were measured transcutaneously with a combined sensor heated at $44^{\circ} \mathrm{C}$ (Oxicapnomonitor 365, Hellige, Freiburg, Germany). Concentration changes of oxyhemoglobin, deoxyhemoglobin and cerebral blood volume in the head were measured with a four wavelength near-infrared spectrophotometer (NIR 500, Hamamatsu, Japan) (12). The optodes emitting and receiving near-infrared light were fixed in the temporal region $4 \mathrm{~cm}$ apart. The data from the monitors were stored continuously with a sampling rate of $1 \mathrm{~Hz}$ on a laptop. During the entire procedure each infant was filmed with a time-coded camera (JVC Super VHS). From these recordings crying, defined as any vocal expression, including sobbing and whimpering, was determined.

When the infant was quiet, baseline values were recorded. An assistant, not involved in the study, gave $2 \mathrm{~mL}$ of the test fluid slowly into the mouth. The heel was warmed with an infrared warmer without touching the skin. An experienced nurse wiped the heel with alcohol, pricked the heel on the side with a 5-mm microlancette, collected the blood with a container, sampled the final drop on a glucose-stick, fixed an adhesive plaster and repositioned the foot. She was instructed not to speak and to touch only the sampled foot. The protocol allowed a pacifier when the baby continued to be excited for more than $3 \mathrm{~min}$. This happened only in one patient, and on both occasions (with sucrose and with water).

The nurse and the principal investigator were asked to guess, at the end of the procedure, whether they thought the baby had received sucrose or placebo.

\section{Data Analysis}

All data were analyzed before the code was broken; before the identity of the sucrose and the placebo groups were known. For each monitored variable criteria allowing quantification were defined before analysis:

Heart rate. Difference between baseline (mean of 20 values) and after heel prick for blood collection (mean of five peak values) and recovery time (time interval between end of blood collection until heart rate returned to baseline values plus two standard deviations).

Respiration. Recovery time (time between end of blood collection and return to regular breaths).

Transcutaneous $\mathrm{Po}_{2}$. Difference between baseline and lowest value during procedure and difference between baseline and highest value during procedure.

Transcutaneous $\mathrm{PCO}_{2}$. Difference between baseline and lowest value during procedure and difference between baseline and value $10 \mathrm{~min}$ after end of blood collection.

Cry. Relative time of crying during heel prick and blood collection and time in seconds between end of blood collection to the first 20 -s period without crying.

Cerebral near-infrared spectroscopy. Cerebral oxyhemoglobin, deoxyhemoglobin, and total blood volume.

The printouts of every session were classified by three observers; each was asked, independently, whether there was an increase, a decrease, or no change after the heel prick.

\section{Statistics}

A minimal sample size of 15 was calculated to detect a difference of $25 \%$ from baseline heart rate with $90 \%$ confidence. Values from the sucrose and the placebo group were compared with the Wilcoxon signed rank test using standard software (JMP on Macintosh).

\section{RESULTS}

Median increase of heart rate was 34 beats per minute (bpm) (range 12 to 53) in the sucrose group and $51 \mathrm{bpm}$ (range 22 to 18 ) in the placebo group. The difference between the two groups is statistically significant ( $p=0.005$ ) (Fig. 1).

Infants who received sucrose cried for a significantly shorter period than those who were given placebo before the heel lance $(p=0.002)$ (Fig. 2). The physiologic characteristics that were 
Table 1. Physiological characteristics measured in all 16 infants

\begin{tabular}{|c|c|c|c|c|c|c|}
\hline \multirow[b]{2}{*}{ Characteristic $^{a}$} & \multirow{2}{*}{$\begin{array}{c}\text { Sucrose group } \\
\text { median }\end{array}$} & \multirow{2}{*}{$\begin{array}{l}\text { Controls } \\
\text { median }\end{array}$} & \multicolumn{4}{|c|}{ Difference } \\
\hline & & & Median & 1st quartile & 3rd quartile & $p$ \\
\hline Increasc in heart rate (bpm) & 35.1 & 51.3 & -16.0 & -0.9 & -29.8 & 0.005 \\
\hline Recovery time for heart rate (s) & 80.5 & 101.5 & -53.0 & 0.0 & -96.0 & 0.05 \\
\hline Recovery time for respiration (s) & 25.0 & 47.5 & -20.0 & -4.0 & -44.0 & 0.05 \\
\hline Crying ( $\%$ of whole intervention) & 71.5 & 93.5 & -10.0 & -3.0 & -33.0 & 0.002 \\
\hline Recovery time until crying stopped (s) & 9.5 & 39.0 & -1.5 & 12.0 & -23.0 & 0.31 \\
\hline $\mathrm{tcPO}_{2}$ max. increase $(\mathrm{kPa})$ & 1.2 & 1.6 & -0.4 & 0.2 & -0.7 & 0.09 \\
\hline $\mathrm{tcPO}_{2}$ max. decrease $(\mathrm{kPa})$ & 0.5 & 0.7 & -0.2 & 0.0 & -0.5 & 0.12 \\
\hline $\mathrm{tcPO}_{2}$ (difference between baseline and $10 \mathrm{~min}$ after end of intervention) $(\mathrm{kPa})$ & 1.1 & 1.4 & -0.2 & -0.1 & -0.6 & 0.05 \\
\hline $\mathrm{tcPCO}_{2}$ max. decrease $(\mathrm{kPA})$ & 0.5 & 0.5 & 0.0 & 0.2 & -0.4 & 0.09 \\
\hline $\mathrm{tcPCO}_{2}$ (difference between baseline and 10 min after end of intervention) ( $\mathrm{kPa}$ ) & 0.2 & 0.2 & -0.1 & 0.1 & -0.3 & 0.21 \\
\hline
\end{tabular}

a $\mathrm{tcPO}_{2}$ and $\mathrm{tcPCO}_{2}$, transcutaneous oxygen and carbon dioxide tension, respectively.
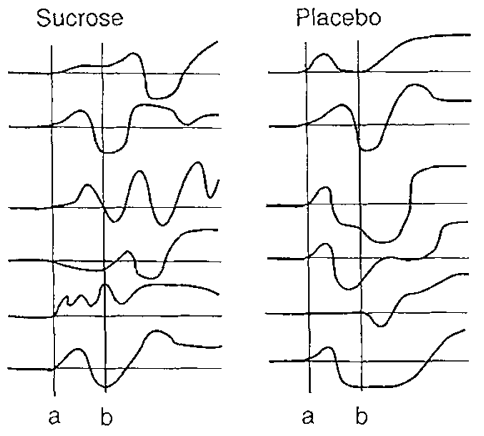

Figure 3. Recordings of transcutaneous oxygen tension in six infants with sucrose and placebo. $a$, heel prick; $b$, end of blood collection. For quantitative data, see Table 1.


Figure 4. Recordings of transcutaneous carbon dioxide tension in six infants with sucrose and placebo. $a$, heel prick; $b$, end of blood collection. For quantitative data, see Table 1 .

explored are given in Table 1. All pointed toward an analgesic effect of sucrose although the number of subjects was too small to rule out the play of chance.

The variability of transcutaneous $\mathrm{Po}_{2}$ and transcutaneous $\mathrm{PCO}_{2}$ is illustrated with recordings from six patients in Figs. 3 and 4. An example of a near-infrared recording showing typical variation of oxyhemoglobin, deoxhemoglobin, and total $\mathrm{Hb}$ reflecting cerebral blood volume is shown (Fig. 5). The Table 2 gives the qualitative changes of oxyhemoglobin, deoxyhemoglobin, and cerebral blood volume. Total blood volume decreased in 5 of 14 instances after sucrose and in 6 of 14 after placebo.

The guesses of nurses and principal investigator whether an infant had received glucose or placebo are given Table 3 . The nurses guessed correctly in $6+9=15$ instances $(56 \%)$ and the



Figure 5. Near-infrared spectoscopy during heel lancing. Oxyhemoglobin $(\mathrm{OxyHb})$ drops and deoxyhemoglobin $(D e o x y H b)$ increases, whereas total $\mathrm{Hb}$ $(t o t H b)$ reflecting ccrebral blood volume does not change significantly.

Table 2. Qualitative analysis of near infrared data

\begin{tabular}{|c|c|c|c|c|c|c|}
\hline & \multicolumn{3}{|c|}{ Sucrose $(n=14)$} & \multicolumn{3}{|c|}{ Controls $(n=14)$} \\
\hline & OxyHb & DeoxyHb & CBV & OxyHb & DeoxyHb & CBV \\
\hline Increase & 8 & 0 & 5 & 9 & 1 & 6 \\
\hline Decrease & 0 & 10 & 0 & 2 & 12 & 1 \\
\hline No change & 6 & 4 & 9 & 3 & 1 & 7 \\
\hline
\end{tabular}

OxyHb, oxyhemoglobin; DeoxyHb, deoxyhemoglobin; CBV, cerebral blood volume.

Table 3. Guesses whether the test solution contained sucrose or

\begin{tabular}{lccccccc} 
& \multicolumn{3}{c}{ Nurse $^{*}$} & & \multicolumn{3}{c}{ Investigator } \\
\cline { 2 - 4 } \cline { 5 - 7 } Test solution & Sucrose & Placebo & Total & Sucrose & Placebo & Total \\
\hline Sucrose & 6 & 7 & 13 & 12 & 4 & 16 \\
Placebo & 5 & 9 & 14 & 9 & 7 & 16 \\
Total & 11 & 16 & 27 & 21 & 11 & 32 \\
\hline
\end{tabular}

* Nurses could not tell whether the infant received sucrose or not on five occasions (not included in this table).

principal investigator in $12+7=19$ instances (59\%). Both guesses are not significantly different from chance.

Median glucose concentration at the end of blood sampling was $5.8 \mathrm{mmol} / \mathrm{L}$ (range 1.7 to 7.8 ) after sucrose and 6.0 $\mathrm{mmol} / \mathrm{L}$ (range 2.9 to 9.1 ) after placebo. There was no correlation between glucose concentration and increase in heart rate or duration of crying.

\section{DISCUSSION}

This study shows a significant calming effect of sucrose on nociceptive reaction of preterm infants to a heel lance mea- 
sured as an increase in heart rate. This confirms a similar observation of Blass and Hoffmeyer (11) in term infants. These authors recorded the amount of crying during a painful procedure. We based our main hypothesis on heart rate recording as this is easier to document, but analysis of crying would have given the same result. Our findings provide further evidence that preterm infants are capable of reacting to a painful stimulus and that this reaction can be reduced by appropriate measures.

In a recently published study sucrose did not reduce the time of crying after a heel stab in term newborn infants (13). In this study 20 infants got sucrose and 20 others not. Although the number of subjects involved in this trial is larger than in our trial, the between-patient design increases the amount of "noise" in the data. Therefore the power to detect a significant difference is low and a positive effect might have been missed. In addition a lower sucrose concentration (7.5\%) was used which may explain at least partly this null result.

Shide and Blass (14) could demonstrate in infant rats that the analgesic effect of sucrose can be reversed by naloxone, an opiate antagonist. They therefore postulated that the mechanism involves activation of endorphins. Transcutaneous $\mathrm{PCO}_{2}$ fell in all instances. This response in association with crying has been described before (15). Decrease of transcutaneous $\mathrm{PCO}_{2}$ was less pronounced with sucrose than with placebo but this difference did not reach statistical significance $(p=0.09)$.

The response of transcutaneous $\mathrm{PO}_{2}$ to the heel lance was inconsistent, in some infants it decreased and in others it increased (Fig. 3). These two patterns associated with crying have been recognized before (16). A decrease in transcutaneous $\mathrm{PO}_{2}$ may be due to an elevation in the intrathoracic pressure resulting in a right-to-left shunt. An increase in transcutaneous $\mathrm{Po}_{2}$ may be the consequence of a reopening of collapsed alveoli and thus a better ventilation-perfusion relation during crying. In term infants a decrease in transcutaneous $\mathrm{Po}_{2}$ has been shown in the first 3 to $5 \mathrm{~d}$ after birth and an increase thereafter. This opposing trend may explain why we were unable to detect a significant difference between sucrose and placebo.

The near-infrared spectroscopy tracings varied widely between individual infants; and sucrose did not alter the response compared with placebo. Cerebral blood volume derived from the sum of oxyhemoglobin and deoxyhemoglobin increased in $39 \%$ of the recordings, decreased in $4 \%$, and did not differ significantly from baseline in the remaining $57 \%$. These findings do not agree with those reported by Brazy (17) who found an increase in cerebral blood volume during crying in $86 \%$ of infants studied. This discrepancy may well be due to a difference in methodology rather than to a population difference.

We have been warned against recommending sucrose as an analgesic and calming intervention in infants for three reasons. First, because sucrose $50 \%$ has a relatively high osmolarity $(2170 \mathrm{mosmol} / \mathrm{L})$. Although many oral drugs given to newborn infants have even a higher osmolarity (18), we would not administer sucrose to immature infants at high risk for necrotizing enterocolitis before oral feeding is established. This policy also should avoid potential hyperglycemia.
Second, because sucrose, which is composed of fructose and glucose, may have a deleterious effect in subjects with fructose intolerance (19). Although this rare side effect cannot be avoided, it is better, we suggest, to expose subjects in a clinic where immediate help is available, as it would not be at home.

Third, sucrose is well known to be the most important factor in the development of caries. Although newborns do not have teeth, they might be conditioned to sweeteners early. Although such an early conditioning of taste has not been demonstrated convincingly, parents might be impressed by the calming effect of sucrose and continue to use it at home. An artificial sweetener would not favor caries but its analgesic effect remains to be demonstrated.

In conclusion, our results show that sucrose reduces the nociceptive reaction in preterm infants. This effect may not be obvious to the caretakers. The use of sucrose in newborn infants should be restricted to alleviate painful procedures. Copious use of sugar should not be encouraged, in view of its high osmolarity, its rare detrimental effect in fructose intolerance, and its relation to dental caries.

Acknowledgments. The authors thank Prof. W. Silverman for critically reviewing the manuscript and the nurses for their help.

\section{REFERENCES}

1. Anand KJS, Hickey PR 1987 Pain and its effects in the human neonate and fetus. N Engl J Med 317:1321-1329

2. Schuster A, Lenard HG 1990 Pain in newborns and prematures: Current practice and knowledge. Brain Dev 12:459-465

3. Zeltzer LK, Anderson CT, Schechter NL 1990 Pediatric pain: Current status and new directions. Curr Probl Pediatr 20:409-486

4. Merskey H, Albe-Fessard DG, Bonica JJ 1979 Pain terms: A list with definitions and notes on usage recommended by the IASP Subcommittee on Taxonomy. Pain 6:249-252

5. Owens ME, Todt EH 1984 Pain in infancy: Neonatal reaction to a heel lance. Pain 20:77-86

6. Johnston CC, Stevens B 1990 Pain assessment in newborns. J Perinatol Neonatal Nurs 4:41-52

7. Lewis M, Thomas D 1990 Cortisol release in infants in response to inoculation. Child Dev 61:50-59

8. Harpin VA, Rutter N 1983 Making heel pricks less painful. Arch Dis Child 58:226227

9. Fitzgerald M, McIntosh N 1989 Pain and analgesia in the newborn. Arch Dis Child 64:441-443

10. McIntosh N, van Veen L, Bramemyer H 1994 Alleviation of the pain of heel prick in preterm infants. Arch Dis Child 70:F177-F181

11. Blass EM, Hoffmeyer LB 1991 Sucrose as an analgesic for newborn infants. Pediatrics 87:215-218

12. Von Siebenthal K, Bernet G, Casaer P 1992 Near-infrared spectroscopy in newborn infants. Brain Dev 14:135-143

13. Rushforth A, Levene MI 1993 Effect of sucrose on crying in response to heel stab. Arch Dis Child 69:388-389

14. Shide DJ, Blass EM 1989 Opioidlike effects of intraoral infusions of corn oil and polycose on stress reactions in 10-day-old rats. Behav Neurosci 103:1168-1175

15. Huch R, Huch A, Rooth M 1983 An Atlas of Oxygen-Cardiorespirograms in Newborn Infants. Wolfe, London, pp 32-79

16. Dinwiddie R, Patel BD, Kumar SP, Fox WW 1979 The effects of crying on arterial oxygen tension in infants recovering from respiratory distress. Crit Care Med 7:50-53

17. Brazy JE 1988 Effects of crying on cerebral blood volume and cytochrome $a a_{3} . \mathrm{J}$ Pediatr 112:457-461

18. Mutz AE, Obladen MW 1985 Hyperosmolar oral medication and necrotizing enterocolitis. Pediatrics $75: 371-372$

19. Cox T 1993 Latrogenic deaths in hereditary fructose intolerance. Arch Dis Child 69:413-415 